\title{
IMPLEMENTASI E-GOVERNMENT BERBASIS ANDROID
}

\author{
Dadan Zaliluddin ${ }^{1}$, Budiman $^{2}$, Ade Rully \\ 1,2,3 Jurusan Informatika, Fakultas Teknik, Universitas Majalengka \\ Jalan K.H. Abdul Halim No.103 Majalengka, Jawa Barat \\ 1adanzuu@gmail.com, \\ ${ }^{2}$ bdm@ft.unma.ac.id, \\ 3 aderuly13@gmail.com
}

\begin{abstract}
Abstrak : Pemanfaatan teknologi Informasi dan komunikasi dalam proses pemerintah bertujuan untuk meningkatkan efisiensi, efektifitas, tranparansi, dan akuntabilitas penyelenggaraan pemerintah. peringkat e-government Indonesia berdasarkan survei PBB tahun 2016 Indonesia mendapat peringkat ke 116, sedangkan Provinsi Lampung masuk dalam kategori "Kurang" dibandingkan dengan provinsi lainnya di Sumatra. Tingginya penetrasi pengguna internet Indonesia dan semakin banyaknya masyarakat yang menggunakan telepon pintar Android menjadi faktor pendukung dalam penerapan aplikasi E-government di Desa Tanjungsari. Penelitian ini bertujuan menciptakan sistem E-government berbasis Android untuk dapat mendukung dalam pengolahan informasi, mengoptimalkan penggunaan teknologi informasi yang tepat guna dalam pengembangan administrasi serta menciptakan tata kelola pemerintahan yang baik. Metode yang digunakan dalam pengembangan sistem E-government berbasis Android ini adalah menggunakan RUP (Rational Unified Process) dengan pengembangan model UML. Implementasi E-government berbasis Android dapat dibangun dan berjalan dengan baik pada perangkat bersistem operasi Android dan menjadi kemudahan akses masyarakat dalam pengembangan administrasi desa tanjungsari tata kelola pemerintahan yang baik kepada masyarakat luas dan menjadi upaya peningkatan tata kelola pemerintahan yang baik dengan menerapkan pelayanan publik berbasis Android. Hampir semua migrasi berkaitan dengan ruang dan waktu, mengenai keterkaitan antara ruang dan waktu ini, para ahli dihadapkan kepada suatu kesulitan untuk menetapkannya. Sehingga definisi terhadap migrasi oleh beberapa ahli sering dirasa adanya kekurang-tepatan
\end{abstract}

Kata Kunci : E-goverment, Android, RUP, PHP, MySQL, Migrasi

\section{PENDAhUluan}

Pemerintahan di seluruh dunia pada saat ini menghadapi "tekanan" dari berbagai pihak untuk meningkatkan kualitas pelayanan publik dan meningkatkan partisipasi aktif dalam pemberian informasi bagi masyarakat serta dituntut untuk lebih efektif. Hal tersebut menyebabkan e-Government atau pemerintahan berbasis elektronik semakin berperan penting bagi semua pengambil keputusan. Pemerintah Tradisional (traditional government) yang identik dengan paper-based administration mulai ditinggalkan. Transformasi traditional government menjadi electronic government (e-Government) menjadi salah satu isu kebijakan publik yang hangat dibicarakan saat ini. Di Indonesia e-Government baru dimulai dengan inisiatif yang dicanangkan beberapa tahun lalu. Di dalam Undang-Undang Nomor 24 Tahun 2009 tentang
Pelayanan Publik dalam bagian menimbang butir b dinyatakan :

Bahwa membangun kepercayaan masyarakat atas pelayanan publik yang dilakukan penyelenggara pelayanan publik merupakan kegiatan yang harus dilakukan seiring dengan harapan dan tuntutan seluruh warga negara dan penduduk tentang peningkatan pelayanan publik. Dalam kaitan tersebut, reformasi birokrasi pemerintahan muncul pertama kali karena adanya keinginan pemerintah untuk memberikan pelayanan terbaik kepada masyarakat seperti yang ditentukan oleh UUD 1945. Peningkatan pelayanan publik (public service) harus mendapatkan perhatian utama dari pemerintah, karena pelayanan publik merupakan hak-hak sosial dasar dari masyarakat (social rihgts ataupun fundamental rights). Landasan yuridis pelayanan publik atas hak-hak sosial dasar diatur dalam ketentuan Pasal 18 A ayat (2) dan Pasal 34 ayat (3) UUD 1945. Dengan demikian UndangUndang Dasar mengatur secara tegas tentang pelayanan 
publik sebagai wujud hak sosial dasar (the rights to receive). Penolakan atau penyimpangan pelayanan publik adalah bertentangan dengan UUD 1945.1 Pelaksanaan public service sebagai hak-hak sosial dasar masyarakat di dalam realita masih banyak hambatan atau penyimpangan. Sering terjadi penyimpangan-penyimpangan dan bahkan kasus-kasus maladministrasi, dan KKN yang bisa berakibat yuridis pada pengenaan sanksi pidana. Pada umumnya, proses pemberian pelayanan kepada publik (masyarakat) dewasa ini dilakukan melalui kontak langsung antara penyedia jasa layanan (birokrasi pemerintah) dengan warga masyarakat. Ternyata, kontak langsung seperti ini telah banyak dimanfaatkan oleh para pelaku interaksi pelayanan baik itu dari pihak birokrat (pemberi layanan) maupun dari pihak warga masyarakat (penerima layanan) Dari sisi pelayan, beberapa oknum pelayan sengaja mencari keuntungan dari pelayanan yang diberikannya misalnya dengan meminta sejumlah bayaran diluar ketentuan yang berlaku. Dari sisi warga masyarakat, beberapa oknum warga masyarakat yang ingin memperoleh layanan secara mudah dengan cara menyogok atau memberi uang "pelican" terhadap oknum aparat pelayan. Praktekpraktek semacam ini tentunya akan berdampak kepada pengguna jasa layanan lainnya, yang pada akhirnya akan berdampak pula pada kualitas pelayanan secara umum. Beberapa hasil survei dari lembaga survei internasional menunjukkan bahwa pelayanan publik di Indonesia masih terburuk di Asia dalam hal pelayanan publik. Demikian pula halnya berbagai kajian yang telah dilakukan oleh para pemerhati pelayanan publik, dengan mana hampir semuanya berkesimpulan bahwa pelayanan publik melalui kontak langsung rentan terhadap berbagai praktek maladministrasi, yaitu suatu praktek yang menyimpang dari etika administrasi atau suatu praktek administrasi yang menjauhkan dari pencapaian tujuan administrasi.

\section{LANDASAN TEORI}

\section{A. Pengertian Government}

Menurut Bank Dunia, E-Government adalah penggunaan teknologi informasi oleh instansi pemerintah seperti Wide Area Networks (WAN) internet, mobile computing, yang dapat digunakan untuk membangun hubungan dengan masyarakat, dunia usaha dan instansi pemerintah lainnya.

Menurut The Worid Bank Group E-Government ialah sebagai upaya pemamfaatan informasi dan teknologi komunikasi untuk meningkatkan efesiensi dan efektivitas, transparansi dan akuntabilitas pemerintah dalam memberikan pelayanan publik secara lebih baik.

Kemudian menurut Depkominfo, mendefinisikan $E$ Government adalah pelayanan publik yang diselenggarakan melalui situs pemerintah dimana domain yang digunakan juga menunjukkan domain pemerintah Indonesia yakni (go.id)

Menurut Clay G. Weslatt (15 Agustus 2007) dalam website, E-Government adalah menggunakan teknologi informasi dan komunikasi untuk mempromosikan pemerintah yang lebih effisien dan penekanan biaya yang efektif, kemudian pasilitas layanan terhadap masyarakat umum dan membuat pemerintah lebih bertanggung jawab kepada masyarakat.

\section{B. Android}

Android merupakan suatu sistem operasi mobile yang berbasis pada sistem operasi linux. Android pertama kali dikembangkan oleh perusahaan startup di California bernama Android, Inc., yang digawangi oleh Andy Rubin, Rich Miner, Nick Sears, dan Chris White pada 2005, Google membeli Android dan mengambil alih proses pengembangannya hingga saat ini. Google merilis versi beta Android SDK (System Development Kit) pada November 2007.

Android menawarkan pendekatan yang menyeluruh dalam pengembangan aplikasi. Artinya, satu aplikasi Android yang dibangun dapat berjalan diberbagai perangkat yang menggunakan sistem operasi Android baik itu smartphone, smartwatch, tablet, dan perangkat lainnya. Perkembangan teknologi Andorid yang begitu pesat juga tidak dapat dilepas dari peranan AOSP (Android Open Source Project) yang bertanggung jawab dalam pengembangan sistem operasi Android dan dipimpin langsung oleh Google.

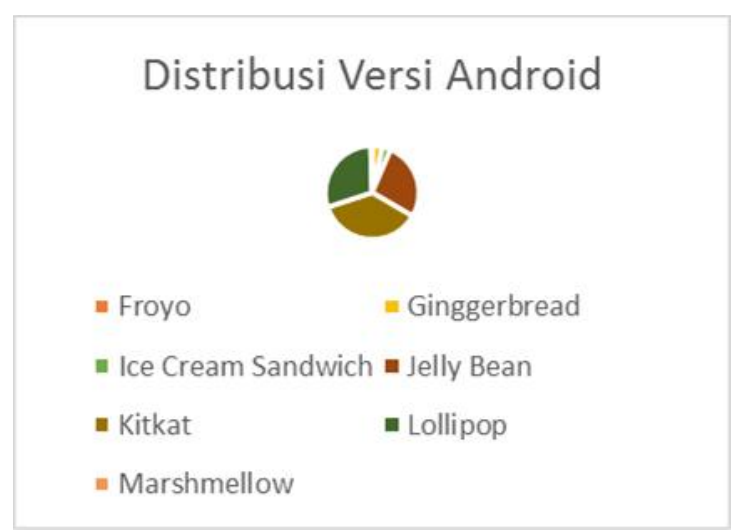

Gambar 1 Distribusi versi Android dalam bentuk pie-chart ${ }^{[4]}$

Gambar 1 memperlihatan dengan jelas bahwa KitKat, Lollipop, dan Jelly Bean merupakan tiga versi android terbanyak yang digunakan di seluruh dunia. Dengan demikian, pangsa pasarnya pun lebih luas dibandingkan dengan mengembangkan aplikasi untuk versi lainnya. Namun, terdapat trade-off dalam pemilihan target versi aplikasi, jika pangsa pasar makin besar maka minimum SDK aplikasi yang dibangun makin kecil yang dengan kata lain fiturnya makin sedikit. Sebaliknya, jika Anda memilih untuk mengembangkan aplikasi dengan minimum SDK yang cukup tinggi, fitur yang bisa dipakai makin banyak, tetapi pangsa pangsa pasar makin kecil. 


\section{App Mit Inventor}

Antarmuka pengguna App Inventor didasarkan pada ide lingkungan pengembangan lantai rendah, langit-langit tinggi (Papert 1980), dan terdiri dari dua bagian: Tampilan Desainer untuk memilih komponen aplikasi, dan Block Editor untuk mengatur perilaku aplikasi. Blok bangunan App Inventor adalah elemen antarmuka pengguna yang umum (tombol, label, pemetik daftar, gambar, dll.) Ditambah dengan fitur perangkat seluler (SMS, GPS, NFC, Bluetooth, dll.) Oleh karena itu, struktur bahasa primitif memungkinkan pengembang aplikasi untuk dengan mudah memanipulasi fungsi perangkat penginderaan yang mudah disentuh, portabel ini.

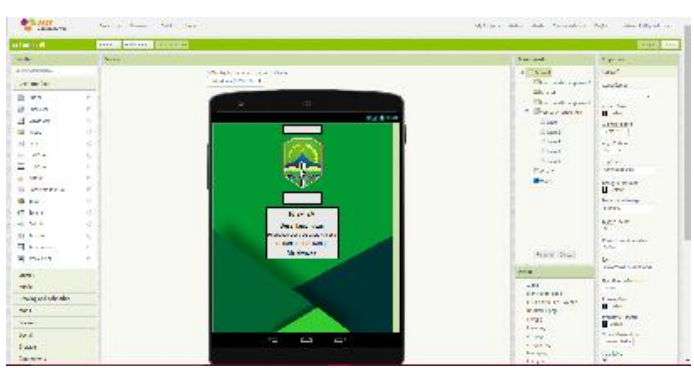

Gambar 2 Tampilan Desain

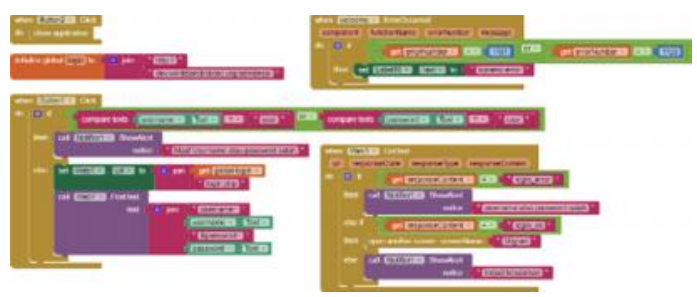

Gambar 3 Block Editor

\section{RUP (Rational Unified Process)}

Rational Unified Process (RUP) merupakan suatu metode rekayasa perangkat lunak yang dikembangkan dengan mengumpulkan berbagai best practises yang terdapat dalam industri pengembangan perangkat lunak. Ciri utama metode ini adalah menggunakan use-case driven dan pendekatan interatif untuk siklus pengembangan perankat lunak. Gambar 4 dibawah menunjukkan secara keseluruhan arsitektur yang dimiliki RUP.

RUP menggunakan konsep object oriented, dengan aktifitas yang berfokus pada pengembangan model dengan menggunakan Unified Model Language (UML).

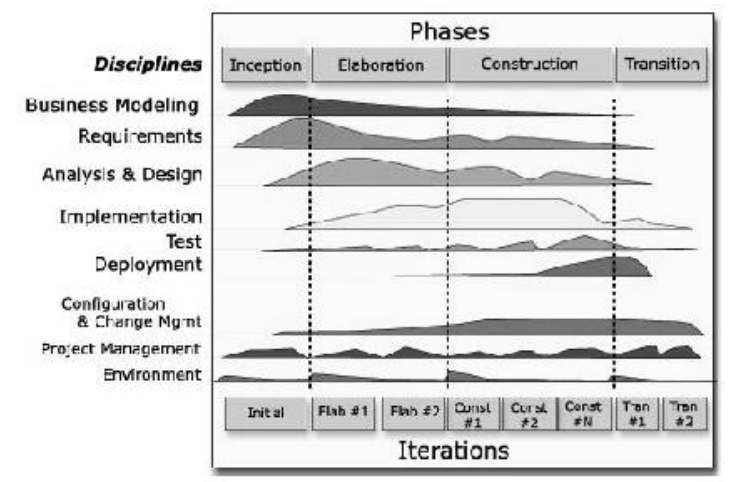

Gambar 2 Arsitektur Rational Unified Process ${ }^{[10]}$

\section{E. Basis Data (Database)}

Pengertian basis data cukup beragam banyak sumber yang telah mendefinisikan, berikut adalah sumber yang kami untuk pengertian basis data:

Menurut Connolly dan Begg, pengertian database adalah kumpulan data yang terhubung secara logis yang dipakai bersama dan deskripsi dari data ini dirancang untuk memenuhi kebutuhan informasi sebuah organisasi.

Dari sumber di atas didapat pengertian database adalah suatu sistem penyimpanan data yang tersusun atas sekumpulan data yang secara logika saling terkait yang dirancang untuk memenuhi kebutuhan informasi perusahaan. Model database relasional adalah sistem yang banyak digunakan karena struktur logikalnya yang sederhana. Pada model relasional seluruh

data disusun secara logikal dalam relasi-relasi atau tabel. Setiap relasi terdiri dari baris, dan kolom dari relasi yang diberi nama tertentu disebut atribut. Sedangkan baris dari relasi disebut tuple dan setiap tuple (baris) memiliki satu nilai untuk setiap attribut.

Database yang tabel-tabelnya saling terhubung dikatakan memiliki relasi. Karena tidak ada relasi yang memiliki dua tuple yang sama, maka setiap baris dapat didefinisikan secara untuk dengan menggunakan primary key. Munculnya sebuah atribut dalam beberapa relasi dapat mempresentasikan hubungan antara tuple dari relasi tersebut. Pemakai Database dapat berupa orang atau program aplikasi. Orang biasanya menggunakan database dari terminal dan mengambil data dan informasi dengan menggunakan query language. Query adalah pemintaan informasi dari database, dan query language adalah bahasa khusus yang user friendly yang memungkinkan komputer menjawab query

\section{F. UML (Unified Modelling Language)}

UML (Unified Modelling Language) merupakan bahasa pemodelan grafis yang digunakan untuk mendesain dan membantu pendeskripsikan sistem perangkat lunak, khususnya sistem yang berorientasi objek. UML mencakup berbagai masalah yang meliputi spesifiasi, visualisasi, 
konstruksi, dan dokumentasi berbagai jenis perangkat lunak sistem, perangkat lunak non-sistem, dan model bisnis. Selain itu, dapat digunakan dalam pengembangan berbagai tahapan, mulai dari analisis kebutuhan sistem sampai implementasi sistem. UML memenuhi persyaratan objek analisis dan desain karena termasuk diagram alernatif untuk menjelaskan statis properti, penggunaan sistem atau komponen, dan sistem arsitektur. $^{[6]}$

\section{G. Pengertian migrasi}

Migrasi diartikan sebagai perpindahan penduduk dengan tujuan untuk menetap dari suatu tempat ke tempat lain melalui batas politik / negara ataupun batas administrasi / batas bagian dari suatu negara.

\section{Metodologi PENELITIAN}

Tahap ini pengembang sistem diperlukan komunikasi yang bertujuan untuk memahami perangkat lunak yang diharapkan oleh pengguna dan batasan perangkat lunak tersebut. Informasi ini biasanya dapat diperoleh melalui wawancara, diskusi atau survei langsung. Informasi dianalisis untuk mendapatkan data yang dibutuhkan oleh pengguna.

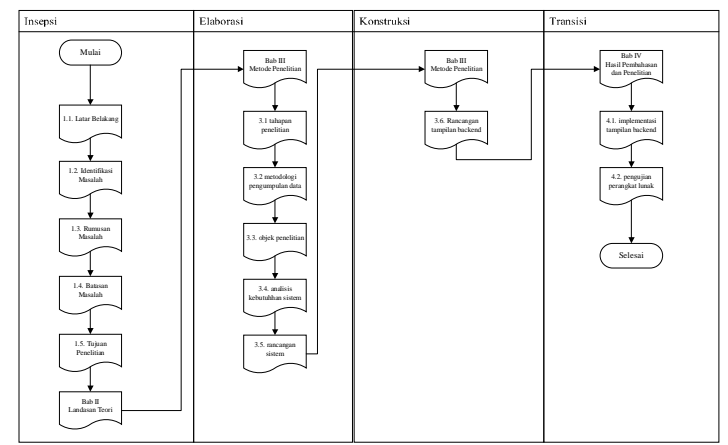

Gambar 5 Kerangka Penelitian

\section{A. Metodologi Pengumpulan Data}

Metodologi pengumpulan data ini untuk sistem yang akan dibuat, penulis menguraikan beberapa metode lain agar pembangunan sistem bisa lebih optimal.

1. Wawancara

2. Studi Kepustakaan (Library Research)

\section{B. Rancangan Sistem}

Rancangan sistem mempunyai dua tujuan yaitu memenuhi kebutuhan kepada pemakai (user) dan untuk memberikan gambaran yang jelas serta rancang bangun yang lengkap kepada pemrogram (developer) dan ahli teknik lainnya yang terlibat dalam pembuatan sistem tersebut

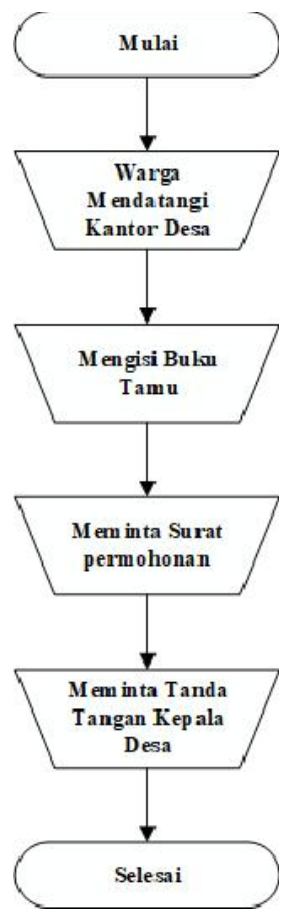

Gambar 6 Flowchart yang sedang berjalan

\section{HASIL DAN PEMBAHASAN}

Usecase diagram adalah diagram yang menggambarkan secara ringkas siapa yang dapat menggunakan system dan apa saja yang bisa di lakukannya.

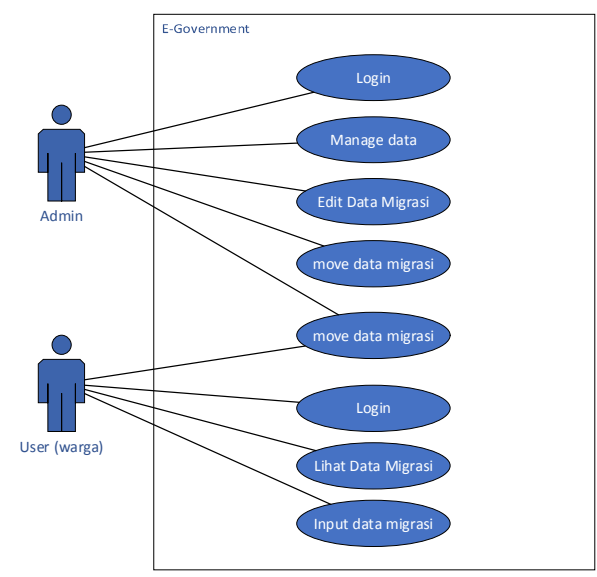

Gambar 7 Usecase Diagram 


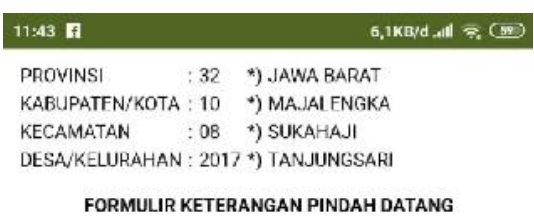

No.475//XIII/DS/2019

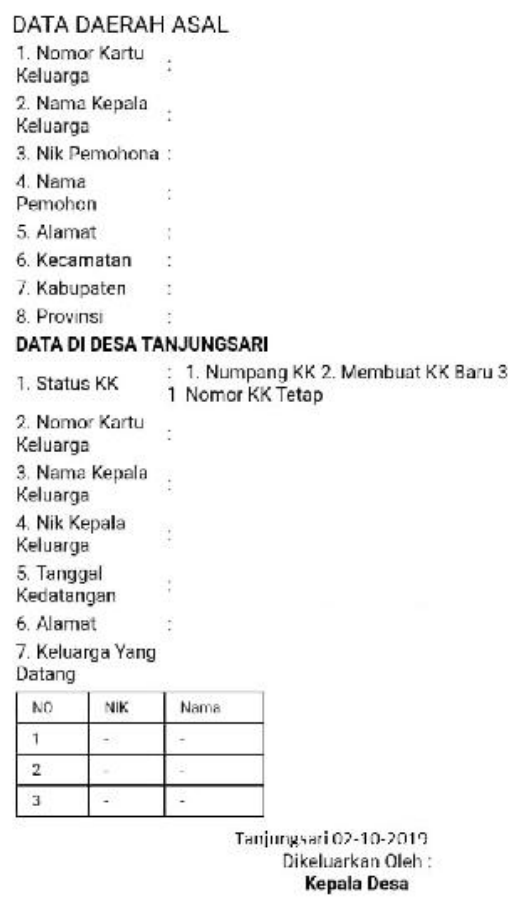

Gambar 8 Tampilan Lihat Formulir Keterangan Pindah Datang

\section{KeSIMPULAN}

\section{A. Kesimpulan}

Dengan dibuatnya Aplikasi Pelayanan Desa Berbasis Android ini , maka diperoleh kesimpulan sebagai berikut:

1. Desa Tanjungsari Kecamatan Sukahaji Kabupaten Majalengka mempunyai Aplikasi Pelayanan Desa Berbasis Android sendiri supaya lebih cepat dalam menjalankan urusan administrasi desa tanpa harus menggunakan paper based administration lagi

2. Dengan adanya aplikasi ini, selain dapat mempercepat dan mempermudah urusan administrasi desa.

B. Saran
Aplikasi Pelayanan Desa Berbasis Android ini masih jauh dari kata sempurna dan masih banyak kekurangannya. Oleh karena itu diperlukan pengembangan dan penyempurnaan lebih lanjut. Adapun saran agar sistem ini dapat berfungsi dengan optimal adalah sebagai berikut.

1. Perlu melakukan pengembangan sistem informasi secara berkesinambungan karena teknologi informasi selalu berubah dengan kebutuhan yang selalu berubah mengikuti perkembangan.

2. Dapat di tambahkan fitur-fitur serta fungsi-fungsi lainnya.

a.Penambahan fitur email ke kepala desa untuk memvalidasi form dengan cara memakai tanda tangan digital

b.Data langsung bisa tersinkronasi dengan Disdukcapil

Untuk mempermudah masyarakat dalam penggunaan aplikasi maka disarankan aplikasi berbasis web dengan patokan dari aplikasi ini.

\section{REFERENSI}

[1] Feridiana, w. (2015). Migrasi. Pengantar kependudukan.

[2] Februariyanti, h., \& zuliarso, e. (2012). Rancang bangun sistem perpustakaan untuk jurnal elektronik. Jurnal teknologi informasi dinamik, 17(2).

[3] Galandi, f. (2017). Pengetahuan \& teknologi. Diambil kembali dari pengetahuandanteknologi.com: http://www.pengetahuandanteknologi.com/2016/09/meto de-waterfall-definisi-tahapan.html

[4] Hansun, s., kristanda, m. B., \& saputra, m. W. (2018). Pemograman android dengan android studio ide. Yogyakarta: andi.

[5] Holle, e. S. (2011). Pelayanan publik melalui electronic government: upaya meminimalisir praktek maladministrasi dalam meningkatan public service. Jurnal sasi, 22.

[6] Mahdia, f., \& noviyanto, f. (2013). Pemanfaatan google maps api untuk pembangunan sistem informasi manajemen bantuan logistik pasca bencana alam berbasis mobile web. Jurnal sarjana teknik informatika. 1.

[7] Makmur, h. (2018). Bab ii landasan teori. Diambil kembali dari anzdoc.com:https://anzdoc.com/bab-iilandasanteorid65c2a0c684e499352212bf392c057a027418.html

[8] Malabay. (2016). Pemanfaatan flowchart untuk kebutuhan deskripsi proses bisnis. . Jurnal ilmu komputer, 12(1).

[9] Marselia, m. (2012). Pembuatan media pembelajaran berbasis film animasi kartun pada pengenalan perangkat keras komputer dalam pembelajaran tik di kelas vii. 27.

[10] Okerlund, j., \& turbak, f. (2013). A preliminary analysis of app inventor blocks programs. 1-3. 
[11] Pokress, s. C., \& dominguez, j. J. (2013). Mit inventor. Enabling personal mobile computing, 1-3.

[12] Puadah, u. (2018). Rancang bangun aplikasi penjualan rajutan online. Majalengka.

[13] Subroto, f. (2018). Audien. Ekonomi, 10.

[14] Sugiharto, t., kadir, a., \& ferdiana, r. (2014). Perancangan mobile application untuk penanganan tindak pidana pelanggaran lalu-lintas menggunakan metode rational unified process. Seminar nasional teknologi informasi dan multimedia 2014, 13-14 